\title{
Preparation and characterization of sintered clay ceramic membranes water filters
}

https://doi.org/10.1515/oms-2019-0005

Received Dec 04, 2018; accepted Apr 15, 2019

\begin{abstract}
Metal oxide ceramic is getting more attention in current times due to their unique pore structures, hydrophilic surfaces, high chemical, thermal and mechanical stabilities which offer avenues for application in water treatment. This paper presents the results of an experimental study on the effects of different ratios of clay, grog, sawdust and bone char on efficiency of ceramic composite water filters. Filter of different designs were developed from clay $(50,60,70,75$ and 80$)|\%|$, sawdust $(15,25$, and 35) $|\%|$, grog (5 and 15$)|\%|$ bone char and $5|\%|$ ratios by volume and sintered at temperature of $900^{\circ} \mathrm{C}$ for 6 hours. The Phase and functional group identification of sintered filter investigated with $\mathrm{x}$-ray diffraction and infrared spectroscopy revealed the presence of mixed phase and hydroxyl functional group on the surface of sintered filter. Field emission scanning electron microscopy (FESEM) revealed the porous nature of the microstructures of the sintered filter elements. The superior ceramic water filter design (C900-50-15-35) with total porosity $35.89 \pm 0.04|\%|$, flow rate $2.05 \pm 0.41|\%|$ and the percent $\mathrm{E}$ coli, nitrite and fluoride removal efficiency: $99.6 \pm 0.40|\%|, 81.17 \pm 0.22|\%|$ and $96.4 \pm 0.42|\%|$ were obtained from this work. Porosity evaluated by BET study for C900-50-15-35 demonstrated an average pore size and surface area of $5|\mathrm{~nm}|$ and $7.30\left|\mathrm{~m}^{2} / \mathrm{g}\right|$, respectively.
\end{abstract}

Keywords: sintering, ceramic filter, grog, microstructure, porosity

\section{Introduction}

Lack of clean water for use by rural communities in developing countries is of great concern globally. Contam-

\footnotetext{
*Corresponding Author: Enyew Amare Zereffa: Applied Chemistry Dept, School of Applied Natural Sciences, Adama Science \& Technology University, Ethiopia; Email: enyewama@yahoo.com Tegene Desalegn: Applied Chemistry Dept, School of Applied Natural Sciences, Adama Science \& Technology University, Ethiopia

๑ Open Access. ( 2019 E. A. Zereffa and T. Desalegn, published by De Gruyter

inated water causes water-borne diseases such as diarrhea, which often leads to deaths, children being the most vulnerable [1, 2]. Chemical contamination of drinking water sources is also a concern for millions of people and long-term exposure to chemical pollutants can have serious health implications. Fluorine is one of such contaminants that contaminate water [3]. Currently, many technologies such as chemical precipitation [4], adsorption [5], ion exchange [6], membrane filtration [7], electrochemistry [8], phyto-remediation [9] and others like metal oxides and graphene have been widely employed to purify wastewater [10]. The practice of using metal oxides and ceramic membranes for purification of contaminated water is developing through inactivating gram-positive bacteria, gram-negative bacteria, spore cells [11-16], adsorbing heavy metals [17, 18], and removing halogenated hydrocarbons, radio nuclides, organic compounds, fluoride and anions from contaminated water [19-21]. The clay-containing aluminum and iron oxide surfaces and chemical modified clay resulted into higher fluoride adsorption by exchange of $\mathrm{OH}^{-}$ions with $\mathrm{F}^{-}$[22]. Adsorption of fluoride by fired clay soil and fired clay soil pillared with tea leave ash was also reported [23, 24]. Low-cost clay ceramic water filter is a porous ceramic medium to filter microbes or other contaminants from water which is more easily recovered after fouling because ceramics can withstand harsh chemical and thermal cleaning methods [25-27]. Clay ceramic water filters have removed materials that affect appearance, bad tastes and further remove contaminants that can cause disease and illness from water for large-scale water [28]. The World Health Organization (WHO) encourages its use as household water treatment systems (HWTS) for effective treatment of drinking water $[29,30]$.

Ceramic water filters are prepared by mixing clay with pore formers, shaped into a filter with a press, and fired in a furnace. The pore-formers leave small pores of different sizes, which can filter out the majority of harmful microbes [31-38].

Ceramic filters membrane has been attractive to the researchers in the last decade due to their superior thermal and chemical stability, better mechanical strength, and high resistance to acid and base and has good defouling properties [39]. The successful applications of ceramic fil- 
Table 1: Composition of filter design in volume ratio by percentages $|\%|$ and sintering temperature.

\begin{tabular}{ccccccc}
\hline No & Filter Design & Clay & Grog & Sawdust & Bone char & Sintering Temperature $\left({ }^{\circ} \mathrm{C}\right)$ \\
\hline 1 & C900-50-15-35 & 50 & 15 & 35 & 5 & 900 \\
2 & C900-60-15-25 & 60 & 15 & 25 & 5 & 900 \\
3 & C900-70-15-15 & 70 & 15 & 15 & 5 & 900 \\
4 & C900-70-5-25 & 70 & 5 & 25 & 5 & 900 \\
5 & C900-75-5-20 & 75 & 5 & 20 & 5 & 900 \\
6 & C900-80-5-15 & 80 & 5 & 15 & 5 & 900 \\
\hline
\end{tabular}

ters for the wastewater treatment were found in the chemical industry, metal industry, textile industry, food and beverage [40]. The use of clay and fly ash as the raw material for crack-free ceramic membranes filtration showed good performance for treatment of textile wastewater and heavy metal from aqueous solutions [41, 42]. Ceramic membranes made from clays and phosphates were suggested to be used as a previous clarification step in textile water treatment [43]. In another study, simple ceramic filters manufactured from clay soil and rice can be applied to remove more than $95 \%$ of $\mathrm{Fe}$ through oxidation, coprecipitation, and filtration [44]. The ceramic filter surface is regenerated through periodic scrubbing to reduce surface deposits that slow down filtration rates [45].

A clay water filter has many advantages due to its lightweight, portable, low-cost, requires no chemicals, and is simple to use; it can be produced locally, using naturally available clay and other materials. The pore size and surface charge of a ceramic water filter determine its ability to remove particles and pathogens from water [46]. The effort of this research project was to develop a clay composite ceramic water filter from locally available materials like clay, sawdust, grog and bone char for household water treatment and study the efficiency of the filter in removing microorganisms (E. coli), and chemical contaminants: fluoride, and nitrite from the water.

\section{Methodology}

\subsection{Materials}

First, the raw materials used for the production of the filters clay, water, grog, and burnout materials (hardwood sawdust) and bone char (charred at $400^{\circ} \mathrm{C}$ ) were collected. Each of the basic material was subjected to various physical treatments before use for the preparation of the filters. The treatment includes sun drying, crushing and grinding of clay (with piston and mortar), and sieving to obtain fine uniform particle sizes. The Grog used for this work (fired clay without burnout materials) was prepared from fresh dried sieved clay fired at $800^{\circ} \mathrm{C}$.

\subsection{Processing of ceramic filters}

For the preparation of different designs of the ceramic filter; sieved clay powder, grog, bone char, and combustible materials were taken in the required proportion, mixed for more than one hour in dry mixture and water was added uniformly on a dry mix according to the procedure developed $[47,48]$. The blends were again mixed in wet by wedging and rolling to get a homogenous uniform mixture and the wet mixture was divided into blocks. The blocked clay mixtures were molded into frustum shape. The manufactured filter elements have a $10.0 \mathrm{~cm}$ top diameter, $15.0 \mathrm{~cm}$ height, $5.0 \mathrm{~cm}$ bottom diameter, and $1.10 \mathrm{~cm}$ wall thickness. The shaped filters were allowed to sundry for about two weeks. Once the filters were completely dried they were sintered in muffle furnace at $900^{\circ} \mathrm{C}$ for a period of 6 hours gradually starting from room temperature with an intermediate stay time $1 \mathrm{hr}$ at $500^{\circ} \mathrm{C}$ for combustible material removal in the initial heat treatment. Afterward, the filters were left to cool gradually until the temperature reached room temperature. Once cooled, the filters were soaked in water for 24 hours and tested for their clean water flux. The selected filters were washed with distilled water, dried in an oven, packed properly in plastic bags to protect them from any contamination and made ready for the different tests. The percentage of sawdust, clay, grog, bone chare, and sintering temperature were varied in different designs of the ceramic filter (Table 1).

\subsection{Flow Rate}

Flow rates were measured from the water source with the same turbidity as the input for the filter. Flow rate testing is an important quality assurance step which indicates the rate at which water passes through the filter element. So, 
all the produced filters for this work were fully immersed in distilled water and soaked for 24 hours to ensure full saturation of filters at the beginning of the test and to achieve standardized results. Once soaked, the filters were transferred onto a flow testing rack. These were designed to drain the water away and most importantly, to stop water from dripping into the filters below and thus altering the flow rate readings. Each of the filters was filled to the brim with water. Once the filter was filled to the brim, a timer was started for 1 hour. The filter was filled with influent and repeatedly re-filled to the brim level for 1 hour. After an hour, the filter was removed from the rack and the flow rate of each filter was measured with a measuring cylinder.

\subsection{Escherichia coli test}

The water used for the bacterial test was collected from Modjo River which is contaminated with pathogenic bacteria by purposive sampling techniques [49]. Influent samples were diluted before filtering through a membrane filter. Membrane filtration was used to determine the $E$. coli concentration of the influent and effluent samples of the filters. Samples were filtered in triplicate through 47-mm diameter and $0.45-\mu \mathrm{m}$ pore size cellulose ester filters of Millipore. The membranes were incubated on agar for 1624 hours at $37^{\circ} \mathrm{C}$. The $\log 10$ reduction value is used to describe the removal efficiency in case the bacteria removal approaches and changed to $100 \%$.

\subsection{Fluoride Removal Efficiency}

In this work Ion-Selective Electrode (Orion Model 940 Expandable Ion Analyzer) was used to determine the fluoride removal efficiency of five filters on the synthetic water samples of sodium fluoride. In this case, a solution with $10 \mathrm{mg} / 1$ of fluoride ion concentration was filtered through each filter media and the filtrate was then analyzed for residual fluoride concentration. Other solutions, for calibration of the fluoride selective electrode, were prepared from the stock solution by dilution with distilled water. In order to determine the extent of complex fluoride in the samples, calibration and determination were carried out by addition of TISAB. For the preparation of TISAB 500ml distilled water was placed in $1 \mathrm{~L}$ beaker and $7 \mathrm{~g}$ tri-sodium citrate, $56 \mathrm{gm}$ sodium chloride and 2gm (EDTA) were added to it and stirred to dissolve, and $57 \mathrm{~mL}$ glacial acetic acid, $5 \mathrm{M}$ sodium hydroxide was added until the $\mathrm{pH}$ was reached 5.3 and transferred to a $1 \mathrm{~L}$ volumetric flask and diluted with distilled water to the mark of flask. $20 \mathrm{~mL}$ of fluoride solu- tions with different fluoride concentrations: $1 \mathrm{mg} / \mathrm{L}, 2 \mathrm{mg} / \mathrm{L}$, $3 \mathrm{mg} / \mathrm{L}, 4 \mathrm{mg} / \mathrm{L}$, and $5 \mathrm{mg} / \mathrm{L}$ were prepared and $2 \mathrm{~mL}$ TISAB was added to each solution for the calibration of the electrode. The potential reading of each concentration was taken and the graph of potential ( $\mathrm{E}$ in $\mathrm{mv}$ ) verses the logarithm of concentration ( $\log \mathrm{C}$ in $\mathrm{mg} / \mathrm{L}$ ) was drawn then the slope of the graph and $r^{2}$ were calculated to check the accuracy of the measurement.

\subsection{Nitrite Removal Efficiency}

The removal efficiency of each filter was determined in accordance with the USEPA approved Diazotization Method [18] for reporting wastewater and drinking water analyses by filtering synthetic sodium nitrite solution of strength $10.98 \mathrm{mg} / \mathrm{L}$. The performance of each individual filter was evaluated in triplicate by comparing the concentration of nitrite before and after filtration and without any surface modification of the filters by acid. A stock solution of sodium nitrite $(1000 \mathrm{mg} / \mathrm{L})$ in deionized water was used to prepare a $50.0 \mathrm{mg} / \mathrm{L}$ working standard in a $100 \mathrm{ml}$ volumetric flask. From this working solution, a series of calibration standards of $0.2 \mathrm{mg} / \mathrm{L}, 0.4 \mathrm{mg} / \mathrm{L}, 0.6 \mathrm{mg} / \mathrm{L}, 0.8 \mathrm{mg} / \mathrm{L}$ and $1.0 \mathrm{mg} / \mathrm{L}$ sodium nitrite in deionized water were prepared in $100 \mathrm{ml}$ volumetric flasks.

A solution of p-nitro-aniline and 1-naphthol were prepared separately. Nitrite ions in the filtrates under acidic conditions underwent diazotization with p-nitro-aniline and formed a violet colored complex with 1-naphthol. The concentrations of nitrite after filtration were calculated from a calibration plot prepared from the standard sodium nitrite solutions.

\subsection{Total porosity}

The porosity of the ceramic filters was determined using the water absorption test (direct) method. It was a destructive method because three different masses were taken and the average porosity of these three masses the apparent porosity of a ceramic filter was determined. The samples were weighed when dry in the air then saturated in distilled water at room temperature for 24 hours. The water with the samples was then boiled for about two hours and allowed to cool to room temperature for another 24 hours. This was done to ensure that the air in the open pores of the filter samples was replaced by the distilled water. The soaked samples were weighed under distilled water then removed and the surface was wiped with tissue paper and weighed in air. The weight of the wire was subtracted from 


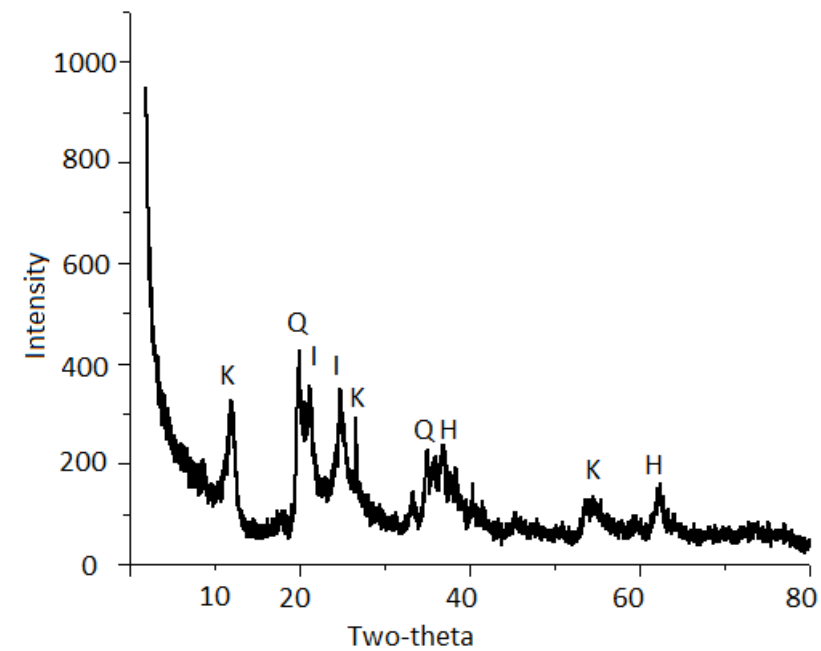

(a)

Figure 1: (a) XRD patterns of raw clay, (b) Sintered filter C900-50-15-35.

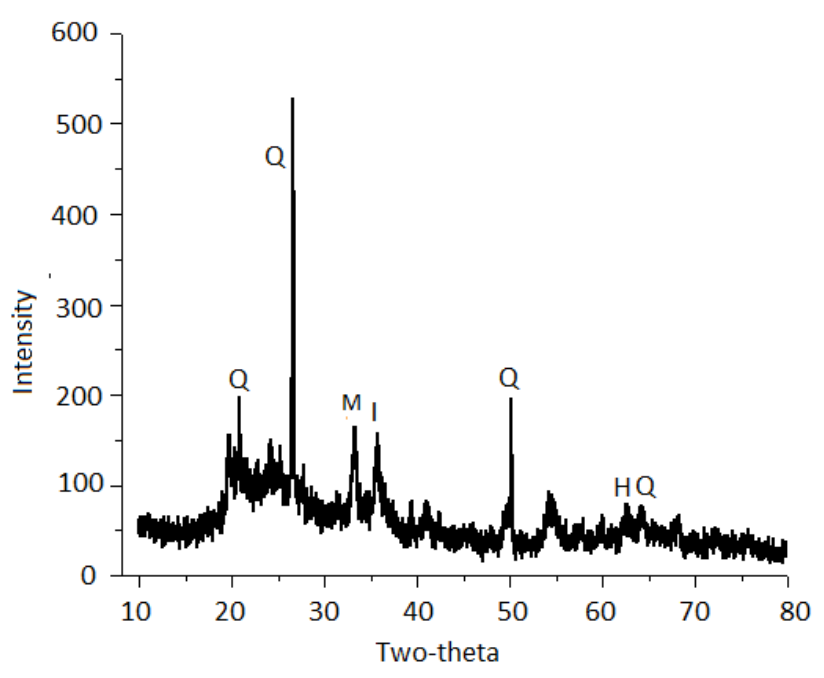

(b) the value obtained while determining the weight of the sample suspended in water. Apparent porosity was then calculated using the expression:

$$
P=100\left[\frac{\text { Wsaturate }- \text { Wdry }}{\text { Wsaturated }- \text { Wunderwater }}\right]
$$

Where; W-saturated is the weight of the specimen when saturated in water, W-dry, is the weight of the dry specimen and $\mathrm{W}$-under water, the weight of the sample underwater.

\section{Results and discussion}

\subsection{X-Ray diffraction \& energy dispersive X-Ray analysis}

Figure 1a \& 1b shows the XRD pattern of the raw clay and fired ceramic filter. The major peaks of raw clay are associated with peaks of kaolin $(2 \theta=12,25$ and 26), Quartz ( $2 \theta$ $=20,35)$, illite $(2 \theta=21,25)$ and Hematite $(2 \theta=36 \& 62)$. The XRD pattern of fired filter is related with Quartz $(2 \theta=$ $21 \& 26)$, Mulite $(2 \theta=33)$, illite $(2 \theta=35)$, Hematite $(2 \theta=$ $36 \& 62)$. The absence of kaolinite at high sintering temperature above $600^{\circ} \mathrm{C}$ due to the formation of metakaolinite from kaolinite, which is an amorphous material and, consequently, displays no XRD peaks [50]. Quartz reflections did not change significantly. A critical observation of the peaks at higher temperature revels that there is significant phase transformation occurs.

The EDX analysis of sintered ceramic filter and chemical composition analysis of raw clay (Figure 5) revealed that the major elements in the filter were like calcium (Ca), aluminum (Al), silicon ( $\mathrm{Si})$, oxygen $(\mathrm{O})$, iron $(\mathrm{Fe})$, carbon (C) and phosphorous (P). The presence of other elements like copper $(\mathrm{Cu})$ and tin $(\mathrm{Sn})$ may be due to the adsorption of other ions on the surfaces of the filter from the contaminated water during filtration. Trace toxic heavy metals like $\mathrm{Pb}, \mathrm{Cd}, \mathrm{Hg}$, and As which could have negative impacts on human health are not fund in the sintered ceramic filter.

\subsection{Porosity and flow rate}

The total porosity and flow rate of the filters as a function of the percentage of clay material content is shown in Figure 3 and Table 2. The data indicated that the porosity was inversely proportional to the percentage of clay. The porosity of the prepared filters increased with an increase in the percentage of burnout material incorporated in the compositions of the filters. This is evident from the total porosity of the filter C900-50-15-35 having the highest ratio of sawdust (35\%), porosity (35.9\%), and that of c900-80-5-15 with low sawdust (15\%) has porosity of $(17.7 \%)$. The flow rate of the filters also decreased with increasing of the \% of clay for C900-50-15$35(2.05 \pm 0.41 \mathrm{~L} / \mathrm{h}), \mathrm{C} 900-60-15-25(1.97 \pm 0.23 \mathrm{~L} / \mathrm{h}), \mathrm{C} 900-70-$ $15-15(1.16 \pm 0.15 \mathrm{~L} / \mathrm{h})$ and increased for filters, C900-75-5-20 $(2.22 \pm 0.26 \mathrm{~L} / \mathrm{h}), \mathrm{C} 900-80-5-15(2.21 \pm 0.40 \mathrm{~L} / \mathrm{h})$ and C900-70-5$25(2.94 \pm 0.38 \mathrm{~L} / \mathrm{h})$, The slight increased in flow rate of the first two filter was due to the volume of grog reduced from $15 \%$ to $5 \%$ and small fractured observed in their microstructures. The anomalous flow rate observed in C900- 


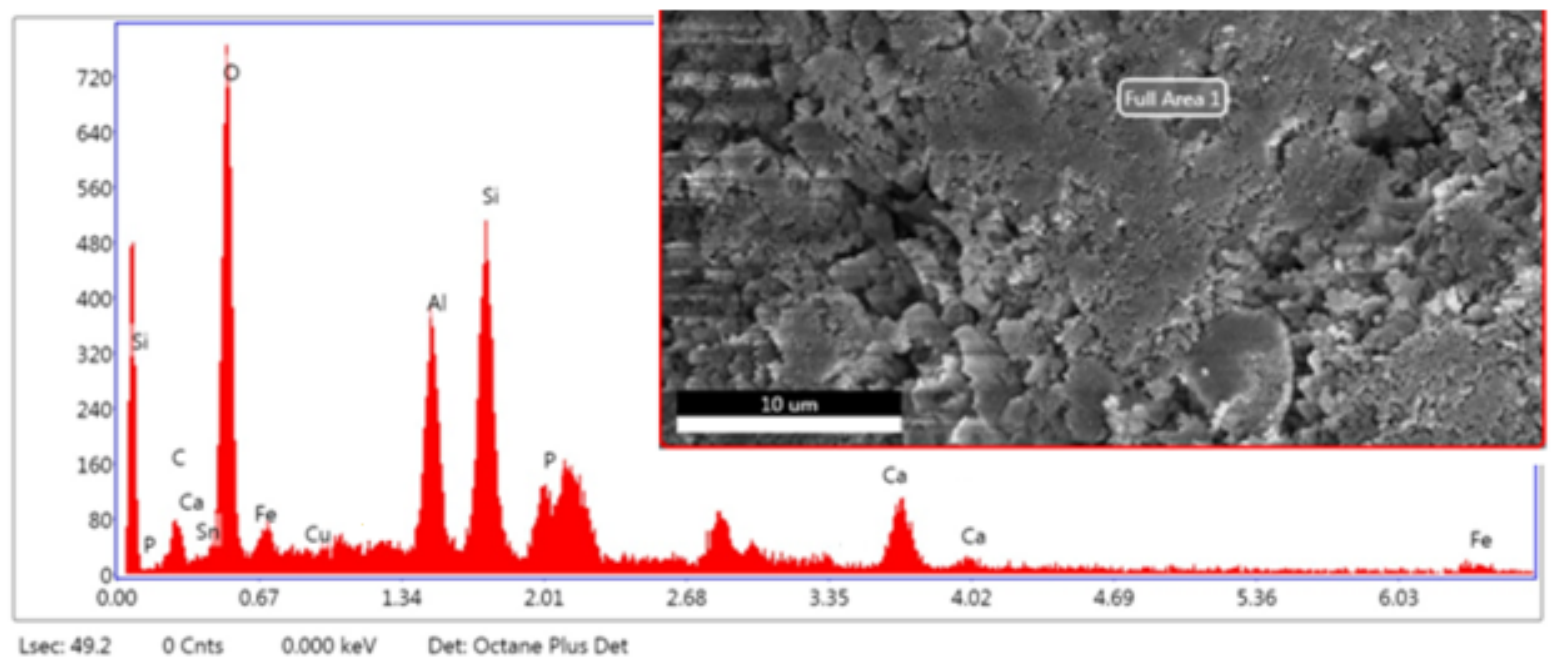

Figure 2: EDS spectrum of C900-50-15-35 used sintered ceramic filter.

Table 2: Test results of basic parameters determined by different filter designs.

\begin{tabular}{cccccccc}
\hline No & Filter Design & E. Coli $|\%|$ & Porosity $|\%|$ & $\begin{array}{c}\text { Flow Rate } \\
|\mathrm{L} / \mathrm{h}|\end{array}$ & $\mathrm{NO}_{2}^{-}|\%|$ & $\mathrm{pH}$ & $\mathrm{F}^{-}|\%|$ \\
\hline 1 & C900-70-15-15 & $99.60 \pm 0.40$ & $29.5 \pm 0.01$ & $1.16 \pm 0.15$ & $87.09 \pm 0.29$ & $7.8 \pm 31$ & $94.4 \pm 0.11$ \\
2 & C900-60-15-25 & $99.36 \pm 0.55$ & $32.95 \pm 0.03$ & $1.97 \pm 0.23$ & $90.13 \pm 0.23$ & $7.6 \pm 26$ & $93.7 \pm 0.01$ \\
3 & C900-50-15-35 & $99.60 \pm 0.40$ & $35.89 \pm 0.04$ & $2.05 \pm 0.41$ & $81.17 \pm 0.22$ & $7.3 \pm 01$ & $96.4 \pm 0.42$ \\
4 & C900-70-5-25 & $87.97 \pm 2.45$ & $25.43 \pm 0.06$ & $2.94 \pm 0.38$ & $71.94 \pm 0.48$ & $7.6 \pm 06$ & $93.1 \pm 0.10$ \\
5 & C900-75-5-20 & $92.67 \pm 1.15$ & $22.61 \pm 0.04$ & $2.22 \pm 0.26$ & $73.69 \pm 0.30$ & $7.9 \pm 06$ & $90.0 \pm 0.12$ \\
6 & C900-80-5-15 & $85.47 \pm 0.57$ & $17.74 \pm 0.04$ & $2.21 \pm 0.40$ & $90.96 \pm 0.52$ & $7.7 \pm 23$ & $93.9 \pm 0.40$ \\
\hline
\end{tabular}

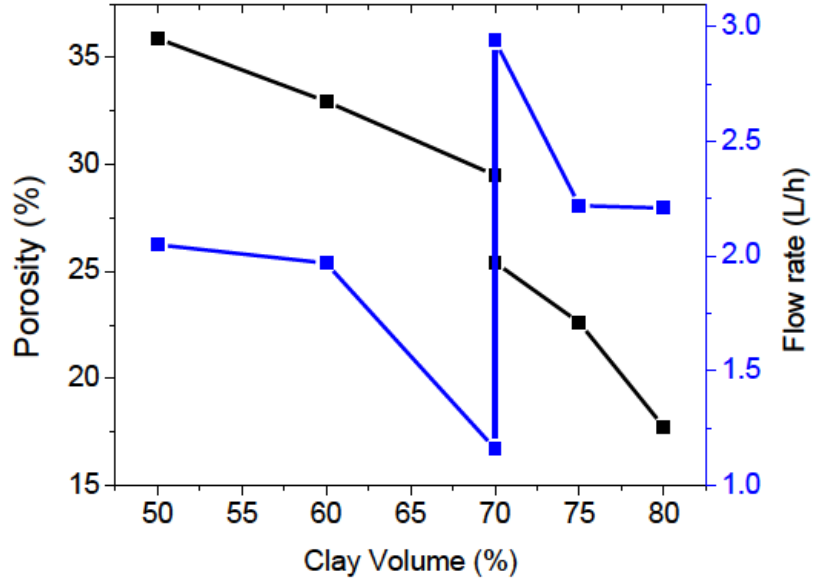

Figure 3: Porosity and flow rate of the filters as a function of $\%$ clay ratios.

$70-5-25(2.94 \pm 0.38 \mathrm{~L} / \mathrm{h})$ was may be due to the large crack formed in the filter body during sintering.

\subsection{The micro-structure of ceramic filter}

The Microstructures investigation of ceramic filter, C90050-15-35 design, with FESEM confirmed the fabrication of porous ceramic filter. Figure 4(a-b) were clearly shows the presence of small pores in the prepared ceramic filter materials, but at higher magnification (Figure $4 \mathrm{c}$ and $4 \mathrm{~d}$ ), isolated \& interconnected pores, the kinds of pores in porous materials that contribute to the process of filtration were observed. This property led to the assumption that these materials could be used as a filter. The E. coli removal efficiencies of filters designs: C900-70-5-25, C90075-5-20 and C900-80-5-15 are in the high risk categories, while that of C900-50-15-35, C900-60-15-25, and C900-70-1515 are in the low risk categories (or above $99|\%|$ ). Porosity of the ceramic filters developed for this project decreased with increase in the amount of burnout materials introduced in the body of the ceramic filters. The porosity of the filter; C900-50-15-35 (35.89 \pm 0.04 is the highest, and its flow rate $2.05 \pm 0.41|\mathrm{~L} / \mathrm{h}|$, nitrite $81.17 \pm 0.22|\%|$ and fluoride $96.4 \pm 0.42|\%|$ removal efficiency. The relative low 

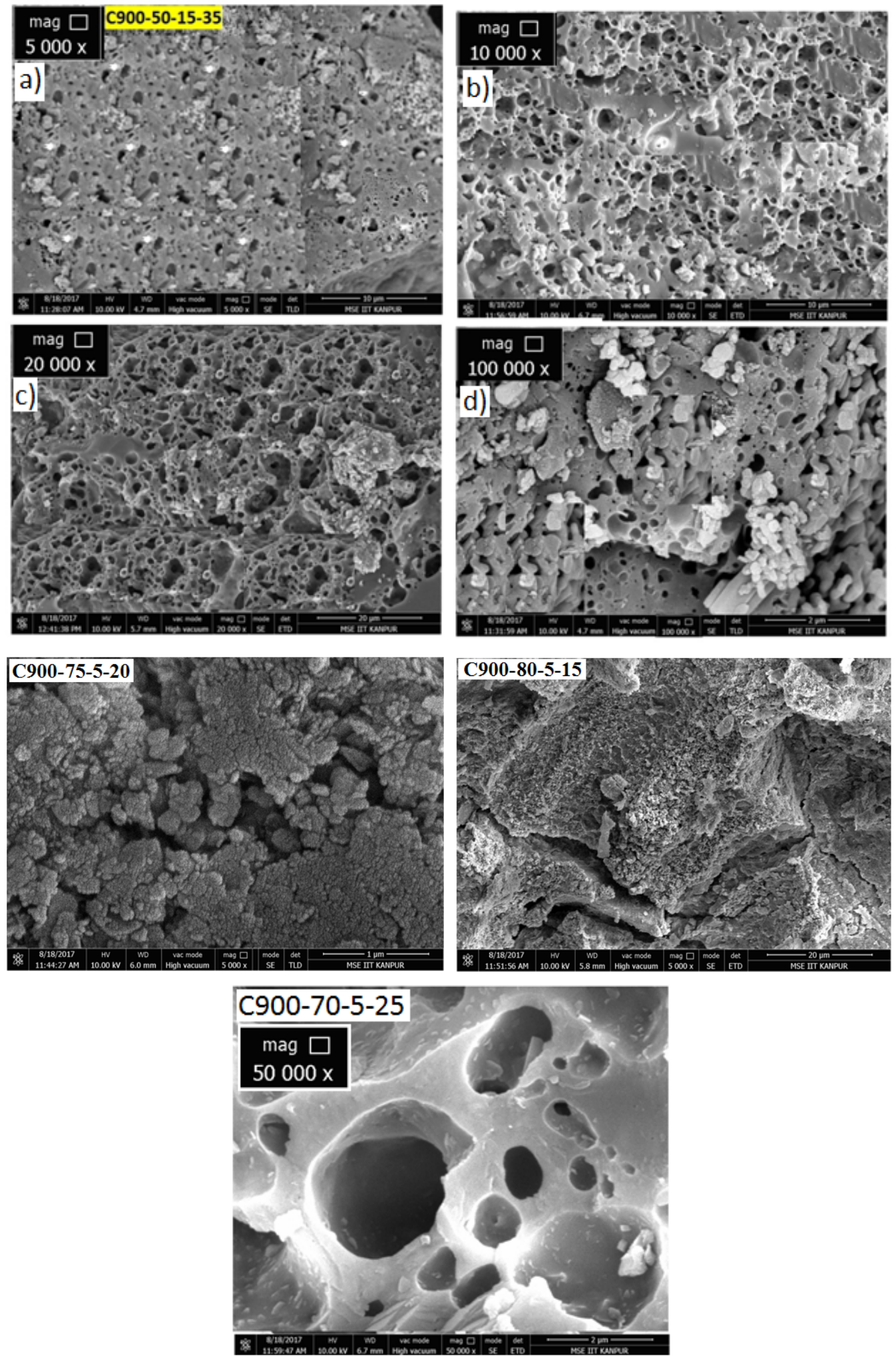

Figure 4: (a-d) The Microstructures of ceramic filter with C900-50-15-35 design micrographs at different magnifications, (e) The Microstructures of ceramic filters C900-80-5-15 and C900-80-5-15 designs, (f) Micrographs of porous C900-70-5-25 at higher magnification 


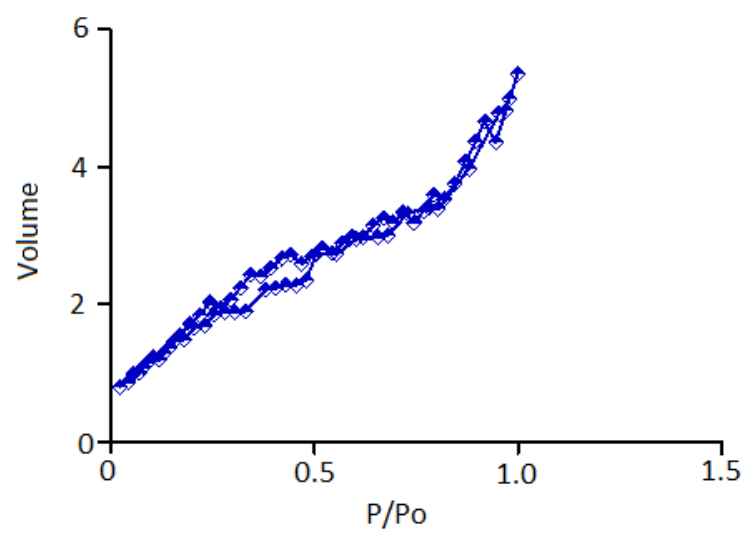

(a)

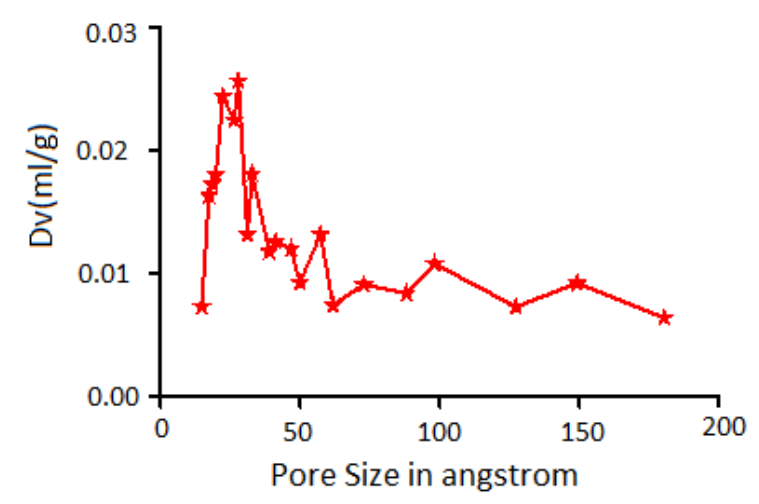

(b)

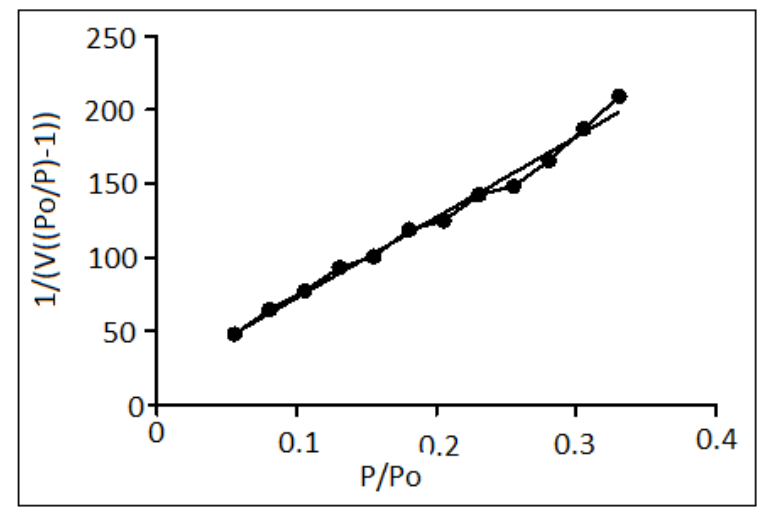

(c)

Figure 5: (a) Adsorption and desorption Isotherm of composite filter C900-50-15-35, (b): Pore size distributions of sintered composite filter C900-50-15-35 in angstrom, (c) Multipoint BET plot for C90050-15-35 filter.

E. coli removal efficiencies of filters with low percentage of grog like: C900-70-5-25, C900-75-5-20 and C900-80-5-15 were might be due to the formation of more fractures during the sintering that leads to high flow rates as it is observed on FESEM images C900-75-5-20 and C900-80-5-15.
Table 3: BET analysis results of selected ceramic filters.

\begin{tabular}{cccc}
\hline Filter design & $\mathrm{S}_{B E T}\left|\mathrm{~m}^{2} / \mathrm{g}\right|$ & $\mathrm{V}_{t}|\mathrm{cc} / \mathrm{g}|$ & $D P|\mathrm{~nm}|$ \\
\hline C900-70-15-15 & 6.29 & 0.008 & $18 \mathrm{~nm}$ \\
C900-60-15-25 & 0.72 & 0.002 & $11 \mathrm{~nm}$ \\
C900-50-15-35 & 7.30 & 0.003 & $5 \mathrm{~nm}$ \\
\hline
\end{tabular}

SBET: BET pore surface area, Vt: Total pore volume, Dp: Average pore diameter

Ceramic filter with C900-70-5-25 design characterized with high average flow rate of about $2.94 \pm 0.38 \mathrm{~L} / \mathrm{h}$ and low percentage E Coli removal efficiency $(87.97 \pm 2.45 \%)$ as it was discussed in section 3.2. The Microstructure analysis of C900-70-5-25 design at higher magnifications revealed the presence of a small number of big size interconnected pores that allow the E coli with filtrate during filtration. This is might be one of the main reasons for the high flow rate and poor filtering effects.

\subsection{BET analysis of sintered ceramic filter}

By analyzing the adsorption isotherms of nitrogen on the mesoporous C900-50-15-35 ceramic filter surface at increasing relative pressure, the BET surface area, pore size and volume were determined. Figure $5 \mathrm{a}$, shows the adsorption \& desorption isotherms characteristics of C900-50-15-35 composite and classified as the Type IV isotherm in accordance to the IUPAC isotherm classification [51]. The mesoporous structure of the developed ceramic filter element makes it a potential adsorbent material. The pore size distribution (Figure 5b) of, C900-50-15-35 filter design, are in the ranges of 20-180 $\AA$, with an average pore size distribution of $5 \mathrm{~nm}$. From the Multipoint BET analysis, in the 0.025 to 0.30 range of $\mathrm{P} / \mathrm{P}_{0}$, the linear plot with correlation coefficient of 0.99 was determined, with the positive slope of 5.45 .

The calculation of specific surface area, total pore volume and average pore diameter based on the BrunauerEmmett-Teller (BET) method for few sintered filters were listed in the Table 3 and Figure 5c. It can be seen that, porosity and pore surface areas of the ceramic filter was influenced by the ratio of clay and burnout materials.

\subsection{FT-IR analysis}

FTIR studies of the filters help in the identification of various forms of the minerals present in the filter elements (Figure $6 a$ and $b)$. In the sintered filter IR studies, the coupled vibrations are appreciable due to the availability of vari- 


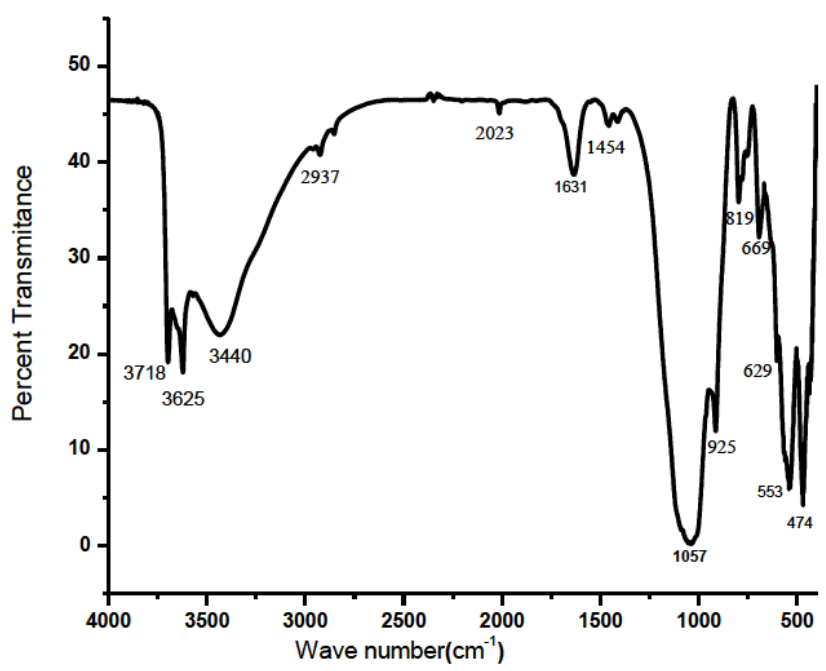

(a)

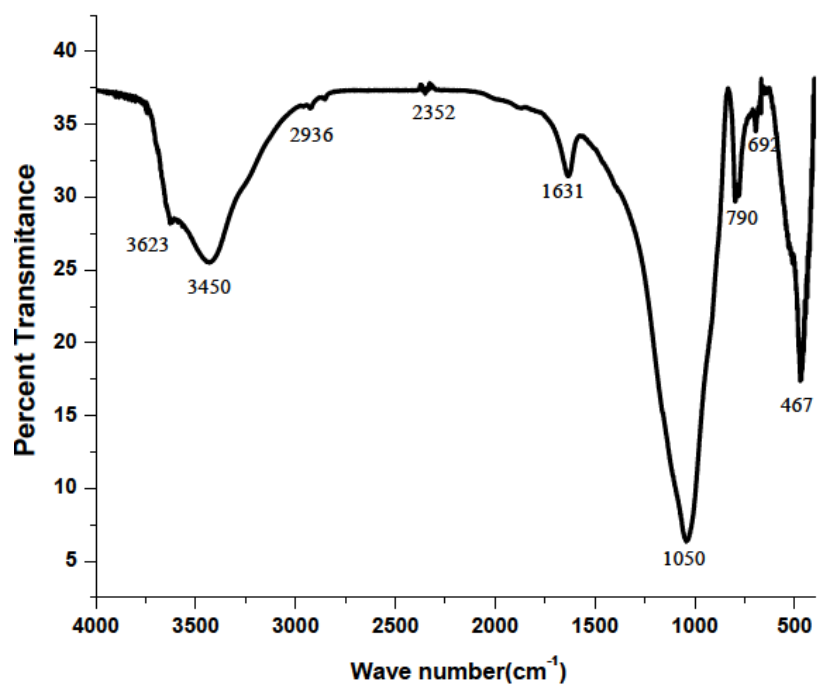

(b)

Figure 6: (a) FTIR Spectrum of sintered C900-50-15-35 ceramic filter with $5 \%$ bone char, (b) The FT-IR spectrum of C900-50-35-15 after used for fluoride removal

ous groups. The vibrations observed at $925 \mathrm{~cm}^{-1}$ indicate the possibility of the presence of hematite [52]. However, a broad band at $3440 \mathrm{~cm}^{-1}$ and a band at $1633 \mathrm{~cm}^{-1}$ in the spectrum of clay suggests the possibility of water of hydration in the sample. $\mathrm{PO}_{4}^{3-}$ stretching mode of vibration characterized by a strong band in the $1000-1150 \mathrm{~cm}^{-1}$ range. The bending vibration of $\mathrm{PO}_{4}^{3-}$ was observed by bands located at $553 \mathrm{~cm}^{-1}$. The FT- IR spectra analysis also revealed the differences between the functional groups in the filter before and after filtration of the NaF solution. It was observed that the hydroxyl groups present on the filter surface were mainly involved in the sorption of fluoride. Anion exchange and electrostatic interaction were suggested as the main mechanisms involved in the sorption of fluoride on the filter. The changes in the stretching frequency of fluoride-treated filter material compared to untreated filter material confirm the chemical modification.

\section{Conclusion}

In this work, six ceramic water filters were developed from different ratios of clay, grog, and sawdust, bone char and sintered at $900^{\circ} \mathrm{C}$. The developed water filters with different designs were used for testing E. coli, nitrite and fluoride ions removal efficiencies from synthetic and contaminated water samples. The variations of the ratio of clay, grog and sawdust influenced the performance of the filters. The filter design, (C900-50-15-35), has the better E. coli removal efficiency $99.6 \pm 0.40|\%|$ and good flow rate $2.05 \pm 0.41$ $|\%|$. Fine-tuning the amount of grog, sawdust and grog is used to control the microstructure of the clay ceramic filter.

Acknowledgement: The researchers would like to acknowledge Adama Science and Technology University Research Affairs for the financial support and OSHO Fluoride Removal Technology Center for providing laboratory facilities

\section{References}

[1] World Health Organization (WHO), Diarrhoea: Why Children Are Still Dying and What Can Be Done, New York: United Nations Children's Fund, 2009.

[2] Clasen T., Schmidt, W., Rabie, T., Roberts, I., Cairncross S., Interventions to improve water quality for preventing diarrhea: a systematic review and meta-analysis. BMJ 334, 2007, 782.

[3] WHO, Guidelines for drinking-water quality, 2011.

[4] Matlock, M.M., Howerton, B.S., and Atwood, D.A., Chemical precipitation of heavy metals from acid mine drainage, Water Research 36, 2002, 4757-4764.

[5] Ali, I. and Gupta, V., Advances in water treatment by adsorption technology, Nat. Protoc 1, 2006, 2661-2667.

[6] Rengaraj, S., Yeon, K. H., and Moon, S.H., Removal of chromium from water and wastewater by ion exchange resins, Journal of Hazardous Materials 87, 2001, 273-287.

[7] Zularisam, A.W., Ismail, A.F., and Salim, R., Behaviors of natural organic matter in membrane filtration for surface water treatment - A review. Desalination 194, 2006, 211-231.

[8] Vasudevan, S. and Oturan, M.A., Electrochemistry: As cause and cure in water pollution-an overview, Environmental Chemistry Letters 12, 2014, 97-108.

[9] Rezania, S., Ponraj M., Talaiekhozani, A., Mohamad, S. E., Din, M. F. M., Taib, S. M., et al., Perspectives of phytoremediation using water hyacinth for removal of heavy metals, organic and 
inorganic pollutants in wastewater. J. Environ. Manag 163, 2015, 125-133.

[10] Upadhyay, R.K., Soin, N., and Roy S.S., Role of graphene/metal oxide composites as photo-catalysts, adsorbents, and disinfectants in water treatment: A review. RSC Adv. 4, 2014, 3823-3851.

[11] Stoimenov, P. K., Klinger, R. L., Marchin, G. L., and Klabunde, K. J., Metal oxide nanoparticles as bactericidal agents, Langmuir 18, 2002, 6679-6686.

[12] Maximous, N., Nakhla, G., Wan, W., and Wong, K., Preparation, characterization, and performance of Al203/PES membrane for wastewater filtration, Journal of Membrane Science 341, 2009, 67-75.

[13] Schmidt, H., Koch, D., Grathwohl, G., and Colombo, P., Micro and macroporous ceramics from pre-ceramic precursors. Journal of the American Ceramic Society 84, 2001, 2252-2255.

[14] Lyckfildt, O., Ferreira F., Processing of porous ceramics by starch consolidation. Journal of the European Ceramic Society 18, 1998, 131-140.

[15] Yang, S., Ryu, I., Kim, Y., Kim, K., Jang, K., and Russell, P., Nanoporous membranes with ultrahigh selectivity and flux for the filtration of viruses, Advanced Materials 18, 2006, 709-712.

[16] Colombo, P. and Bernardo, E., Macro and micro-cellular porous ceramics from preceramic polymers. Journal of Computer Science and Technology 63, 2003, 2353-2359.

[17] Sharma, C., Srivastava, V., Singh, K., Kaul, N., and Weng, H., Nanoadsorbents for the removal of metallic pollutants from water and wastewater. Environmental Technology 30, 2009, 583-609.

[18] Ponder, M., Darab, G., Mallouk, E., Remediation of $\mathrm{Cr}(\mathrm{VI})$ and $\mathrm{Pb}(\mathrm{II})$ aqueous solutions using supported, nanoscale zero-valent iron. Environmental Science \& Technology 34, 2000, 2564-2569.

[19] Darab, G., Amonette, B., Burke, D., Orr, D., Ponder, M., Schrick, B., et al, Removal of pertechnetate from simulated nuclear waste streams using supported zerovalent iron. Chemistry of Materials 19, 2007, 5703-5713.

[20] Malay, K. and Salim, J., Comparative Study of Batch Adsorption of Fluoride Using Commercial and Natural Adsorbent, Research Journal of Chemical Sciences 1, 2011, 68-75.

[21] Huang, Y., Shih, Y., and Chang, C., Adsorption of fluoride by waste iron oxide: The effects of solution $\mathrm{pH}$, major coexisting anions, and adsorbent calcination temperature. J. Hazard. Mater 186, 2011, 1355-1359.

[22] Kofa, P., Gomdje, H., Telegang, C., and NdiKoungou, S., Removal of Fluoride from Water by Adsorption onto Fired Clay Pots: Kinetics and Equilibrium Studies. Journal of Applied Chemistry 2017, 2017, 1-7.

[23] Hauge, S., Osterberg, R., Bjorvatn, K., and Selvig, A., Defluoridation of drinking water with pottery: effect of firing temperature. Scandinavian Journal of Dental Research 102, 1994, 329-333.

[24] Mugs, G., Zewge, F., and Socher, M., Preliminary investigations on the defluoridation of water using fired clay chips. Journal of African Earth Science 21, 1996, 479-482.

[25] Benito, J., Sanchez, M., Pena, P., and Rodríguez, M., Development of a new high porosity ceramic membrane for the treatment of bilge water. Desalination 214, (2007), 91-101.

[26] Faibish, R. and Cohen, Y., Fouling-resistant ceramic-supported polymer membranes for ultrafiltration of oil-in-water microemulsions. Journal of Membrane Science 185, 2001, 129-143.

[27] Mallouk, W., Lukens, D., and Shuh, D., Removal of pertechnetate from simulated nuclear waste streams using supported zerovalent iron. Chemistry of Materials 19, 2007, 5703-5713.
[28] Sobsey, M. D., Stauber, C. E., Casanova, L. M., Brown, J. M., and Elliott, M. A., Point of Use Household Drinking Water Filtration: A Practical, Effective Solution for Providing Sustained Access to Safe Drinking Water in the Developing World. Environmental Science and Technology 42, 2008, 4261-4267.

[29] Brown, J., Sobsey, M., and Proum, S., Improving household drinking water quality, Use of ceramic water filters in Cambodia. WSP Field notes. Phnom Penh, Cambodia: WSP, 2007.

[30] Du Preez, M., Conroy, R. M., Wright, J. A., Moyo, S., Potgieter, N., and Gundry, S. W., Use of Ceramic Water Filtration in the Prevention of Diarrheal Disease: a Randomized Controlled Trial in Rural South Africa and Zimbabwe. American Journal of Tropical Medicine and Hygiene 79, (2008), 696-701.

[31] Doek, S., Simon, B., Dik, B., and Bas, H., Particle Removal from Surface Water with Ceramic Microfiltration. Leeuwarden: The Netherlands, 2007.

[32] Rob, D., Xanat, F., Melanie, P., and Georges, T., Point-of-use water treatment technology investigations in Nepal. Clean Water for Nepal, Inc, Cambridge, MA 02139, 2003.

[33] Mwabi, J.K., Mamba, B.B., and Momba, M., Removal of Escherichia coli and fecal coliforms from surface water and groundwater by household water treatment devices/systems. Int. Journal of Environmental Research and Public Health, 9, (2012), 139170.

[34] Doris, V., Aqua for All Post bus 10723430 BB Nieuwegein Department of Water Management Faculty of the Civil Engineering Delft University of Technology, Kiwa Water Research Groningerhaven 95, 2006, 1-76.

[35] Bogdanchikova, N., Kurbatov, A., Tret'yakov, V., and Rodionov, P., Activity of colloidal silver preparations towards smallpox virus. Pharmaceutical Chemistry Journal 26, 1992, 778-779.

[36] Galdiero, S., Falanga, A., Vitiello, M., Cantisani, M., Marra, V., and Galdiero, M., Silver Nanoparticles as Potential Antiviral Agents. Molecules 16, 2011, 8894-8918.

[37] Yang, G. and Tsai, C., Effects of starch addition on characteristics of porous ceramic membrane substrates. Desalination 233, 2008, 129-136.

[38] Bottino, A., Capannelli, C., Del Borghi, A., Colombino, M., and Conio, O., Water treatment for drinking purpose: ceramic microfiltration application. Desalination, 141, 2001, 75-79.

[39] Jedidi, I., Saïdi, S., Khmakem, S., Larbot, A., Elloumi-Ammar, N., Fourati,, A., Charfi, A., Amar, R.B., New ceramic microfiltration membranes from mineral coal fly ash, Arabian Journal of Chemistry, 2, 2009, 31-39.

[40] Fang, J., Qin, G., Wei, W., and Zhao, X., Preparation and characterization of tubular supported ceramic microfiltration membranes from fly ash, Separation and Purification Technology, 80, 2011, 585.

[41] Nasir, S., Treatment of domestic water using the ceramic filter from natural clay and fly-ash. Journal of Engineering Studies and Research 19, 2013, 71-75.

[42] Palacio, L., Bouzerdi, Y., Ouammou, M., Albizane, A., Bennazha, J., Hernández, A., et al., Ceramic membranes from Moroccan natural clay and phosphate for industrial water treatment, Desalination 245, 2009, 501-507.

[43] Shafiquzzaman, M., Azam, S., Nakajima, J., and Bari, H., Investigation of arsenic removal performance by a simple iron removal ceramic filter in rural households of Bangladesh. Desalination 265, 2011, 60-66. 
[44] Campbell, E., Study of Life Span of Ceramic Filter Colloidal Silver Pot Shaped Model. Agua Solutions, Managua Nicaragua, 2005.

[45] Bielefeldt, A., Kowalski, K., Schilling, C., Schreier, S., Kohler, A., and Summers, R., Removal of the virus to protozoan sized particles in point-of-use ceramic water filters. Water Research 44, 2010, 1482-1488.

[46] Naddafi, K., Mahv, A., Nasseri, S., Kokhtari, M., and Zeraati, H., Evaluation of the efficiency of clay pots in the removal of water impurities. Iranian Journal of Environmental Health Science and Engineering 2, 2005, 12-16.

[47] Hagan, J., Harley, N., Pointing, D., Sampson, M., and Soam, V., Ceramic Water Filter Handbook, Resource Development International, Cambodia, 2008.

[48] ZEREFFA, E.A., BEKALO, T.B., Clay Ceramic Filter for Water Treatment. Materials Science and Applied Chemistry 34, 2017, 74.
[49] Ilker, E. and Rukayya, A., Comparison of Convenience Sampling and Purposive Sampling. Department of Biostatistics, Near East University, Nicosia-TRNC, Cyprus, American Journal of Theoretical and Applied Statistics 5, 2016, 1-4.

[50] Carty, W. M. and Senapati, U., Porcelain-Raw Materials, Processing, Phase Evolution, and Mechanical Behavior. Journal of the American Ceramic Society 8, 1998, 3-20.

[51] Franco, F., Pérez-Maqueda, L. A., Pérez-Rodrıǵuez, J. L., The effect of ultrasound on the particle size and structural disorder of a well-ordered kaolinite. Journal of Colloid and Interface Science 274, 2004, 107-117.

[52] Farmer, V. C., The Infrared Spectra of Minerals. Monograph 4. Mineralogical Society, London, (1974), 331. 